\title{
THE FUNCTIONAL STATE OF THE CARDIOVASCULAR SYSTEM STUDENTS ASTU
}

\begin{abstract}
Аннотация. Исследовано функциональное состояние сердечно-сосудистой системы студентов, занимающихся физической подготовкой на основе метода - контроль за пульсом.

Ключевые слова: фризическая подготовка, частота сердечных сокращений, контроль, пульс, физическая нагрузка.

Abstract. Researched the functional State of the cardiovascular system of the students involved in the physical training based on the method of monitoring pulse.
\end{abstract}

Key words: physical training, heart rate, pulse control, exercise.

У здоровых студентов при хорошем мышечном развитии на занятиях физической подготовкой основным лимитирующим фрактором успешного выполнения упражнений является сердечная деятельность [2]. В учебном процессе для контроля за ее состоянием использовали один из самых простых и информативных методов - контроль за пульсом. Пульсом называется толчкообразные смещения стенок артерий при заполнении их кровью, выбрасываемой при систоле левого желудочка. Этот метод определяет и отслеживает функциональное состояние сердечно-сосудистой системы и повышает эффективность мышечной и фризической нагрузки во время развития двигательной активности и фризических качеств.

Проблемная ситуация состоит в том, что студенты нашего университета имеют низкий результат по некоторым физическим показателям и не умеют использовать метод контроля за пульсом во время выполнения фризической нагрузки. Физическая нагрузка на занятиях важна для развития всех функциональных возможностей организма. При этом ускорение кровообращения играет важную роль в повышении обмена веществ, вызванного мышечной деятельностью. Поэтому определение функциональной способности сердечнососудистой системы студентов совершенно необходимо для оценки их общего состояния и допустимой физической нагрузки [1].

Высокая общая работоспособность организма характеризует высокий уровень развития функциональной способности аппарата кровообращения. Большое внимание в работе сердечнососудистой системы студентов на занятиях физической подготовки уделяется изучению динамики ее показателей.

С этой целью впервые в нашей практике была исследована эффективность учебных занятий со студентами - юношами 2-го курса в количестве 27 человек с использованием метода контроля за пульсом с целью определения 
функционального состояния сердечнососудистой системы. Вначале студенты были обучены правилам измерения пульса, а затем выполнили небольшую физическую нагрузку на развитие физических качеств общей выносливости. Частоту сердечных сокращений (ЧСС) ребята считали по сердечному толчку, положив ладонь на область сердца. Подсчет осуществлялся в состоянии мышечного покоя после небольшого отдыха в течение 10 секунд с пересчетом на минуту. По результатам подсчета условно всех студентов можно разделить на две группы. В первой группе у 16 студентов частота сердечных сокращений составляла от 68 до 72 уд/мин. Во второй группе студентов пульс замедлялся от 46 до 60 уд/мин, что свидетельствовало о их лучшей физической подготовленности. Эту нагрузку они выполняли с отдыхом в 1 минуту. Затем студентам была предложена нагрузка - прыжки вверх через гимнастическую палочку за минуту 48 раз. Пульс ребята подсчитывали на лучевой или на сонной артерии. Средний результат ЧСС у 10-ти юношей завышался до 130 уд/мин, у остальных - до 115 уд/мин. После двухминутного отдыха пульс восстановился.

Проведенные исследования дают основания сделать следующий вывод: после 5-10 минутной физической нагрузки при достаточной подготовленности частота сердечных сокращений не должна превышать 90 уд/мин, а через 1-1,5 часа полностью возвращаться к исходным величинам до нагрузки. Пульс следует подсчитывать до и после физической нагрузки, которая влияет на эффективность занятия и функционального состояния сердечно-сосудистой системы. При резком учащении пульса в покое до 100 уд/мин появляется тахикардия. Состояние при уменьшении пульса до 50 уд/мин считается брадикардией. На частоту сердечных сокращений влияют положение тела, пол и возраст человека. После отдыха пульс следует подсчитывать более длительно - в течение 1-3 мин.

\section{ЛИТЕРАТУРА}

1. Макарова Г.А. Практическое руководство для спортивных врачей. Краснодар, 2000. $-678 \mathrm{c}$.

2. Ярошевич И.Н. Общая физическая и специальная подготовка в системе фризического воспитания в ВУЗе: методическое пособие. - Ангарск: АГТА, 2002. $-84 \mathrm{c}$. 